\title{
İlköğretim Matematik Öğretmeni Adaylarının Öğretim Sürecine Yönelik Öz- Yeterlik İnançları
}

\author{
Nur SIRMACI ${ }^{1}$ (D), Alper Cihan KONYALIOĞLU ${ }^{2}$ iD
}

${ }^{1}$ Atatürk Üniversitesi, Erzurum, Türkiye,nsirmaci@yahoo.com

2 Atatürk Üniversitesi, Erzurum, Türkiye, ackonyali@atauni.edu.tr

\begin{tabular}{|c|c|}
\hline Makale Bilgileri & ÖZ \\
\hline $\begin{array}{l}\text { Makale Geçmişi } \\
\text { Geliş: } 28.10 .2019 \\
\text { Kabul: } 10.11 .2021 \\
\text { Yayın: } 31.12 .2021 \\
\text { Anahtar Kelimeler: } \\
\text { İlköğretim Matematik }\end{array}$ & $\begin{array}{l}\text { Bu araştırmada, ilköğretim matematik öğretmeni adaylarının öğretim sürecine yönelik öz-yeterlik inançları } \\
\text { incelenilmiştir. Araştırmanın örneklemi İlköğretim Matematik Eğitimi Ana bilim dalında öğrenim gören } 98 \\
\text { öğretmen adayıdır. Bu araştırmada erkek öğrencilerin, kız öğrencilere nazaran öğretimi planlama, } \\
\text { uygulama ve değerlendirmeye ilişkin öz-yeterlik inanç puanları daha yüksek bulunmuştur. Araştırmada } \\
\text { elde edilen sonuçla ilgili olarak erkek öğrencilerin öğretmenlik mesleğine bakış açılarının olumlu yönde } \\
\text { olduğunu söyleyebiliriz. Kız öğrencilerin de bu yönde olmaları için öğretim sürecinin her aşamasında öz- } \\
\text { yeterlik inançlarının olumlu şekilde gelişmesi, öğretim sürecinde sağlanmalıdır. }\end{array}$ \\
\hline
\end{tabular}

Öğretmeni Adayları, Öz-

Yeterlik İnançları,

Öğretim Süreci

\section{Preservice Elementary Mathematics Teachers' Self-Efficacy Beliefs Towards Instruction Process}

\begin{tabular}{|c|c|}
\hline Article Info & ABSTRACT \\
\hline Article History & In this study, it was aimed to investigate preservice elementary mathematics teachers' self-efficacy beliefs. \\
\hline Received: 28.10 .2019 & The participants of the study are 98 senior students of primary education mathematics teaching department. \\
\hline Accepted: 10.11 .2021 & In this study, self-efficacy beliefs of male students about planning, application and evaluation of teaching \\
\hline Published: 31.12 .2021 & were found to be higher than female students. Regarding the results of the study, we can say that male \\
\hline Keywords: & $\begin{array}{l}\text { students' point of view towards teaching profession is positive. In order to the female students to view the } \\
\text { teaching profession in this direction, a positive development of self-efficacy beliefs should be provided in }\end{array}$ \\
\hline Preservice Elementary & the teaching process at every stage of the teaching process. \\
\hline
\end{tabular}

Mathematics Teachers,

Self-Efficacy Belief,

Teaching Process

\section{GíRiş}

Öğretimin nitelikli olması için çeşitli faktörler rol oynamaktadır. Bunlardan birisinin öğretim süreci olduğunu söyleyebiliriz. Öğretim sürecinin nitelikli bir biçimde öğrencilere sunulması, bu süreçle ilgili doğabilecek sorunların önlenmesi ve bunun ardından başarılı sonuçlar alınması hususlarında yetkin olunması arzu edilen durumlardan biridir. Öğretimin başarılı biçimde planlanması, uygulanması ve değerlendirilmesi sonucunda öğretim süreci başarıya ulaşabilir (Akt. Duman, 2010). Bunun için öğretim sürecini ve bu süreci etkileyen faktörlerin iyi bilinmesi gerekebilir. Bununla ilgili olarak öğretim sürecini uygulama aşamasında, geleceğin öğretmeni olacak öğretmen adaylarının kendilerine sorabilecekleri "Ben bu işin üstesinden gelebilir miyim?” sorusu akıllara gelmektedir. İşte bu noktada devreye Bandura'nın ortaya 
attığı öz-yeterlik kavramı girmektedir.

Bandura öz-yeterliliği, (a) geçmiş performans değil, gelecekteki eylemler hakkındaki inançlar, (b) sonuçlarla ilgili değil, yetenekler hakkındaki inançlar, beklentiler ve (c) genelleştirilmiş kişisel özelliklerin değerlendirmesi değil, alana özgü bireydeki inançlar (Klassen \& Klassen, 2018) olarak karakterize etmeye çalışmıştır. Öz-yeterlik, öğrencilerin düşünce kalıpları ve duygusal tepkileriyle büyük ölçüde bağlantılı olduğundan (Salem, Mosaad \& Abu, 2014) birey üzerinde çeşitli etkileri vardır. Bireyin etkinlikleri seçmesinde, çaba göstermesinde ve sürdürmesinde (Capri ve ark, 2012; Schunk, 1994) rol alan etkilerin yanı sıra bireyin motivasyonu, başarısı ve öz düzenlemesi üzerindeki etkileri de mevcuttur (Akt. Koç, 2013). Bunlara ek olarak Mart, Filip ve Mien (2014), öz-yeterliğin öğrenmeyi de etkilediğini vurgulamıştır.

Bu etkiler, yüksek ve düşük öz-yeterlik inançları olanlara göre farklılıklar göstermektedirler. Son yıllarda yapılan araştırmalar, öz-yeterlik inancı yüksek düzeyde olan bireylerin, öz-yeterliği düşük düzeyde olanlara nazaran en iyi şekilde performans gösterdiklerini (Web-Williams, 2014), herhangi bir durum karşısında güçlü motivasyona sahip olduklarını (Morgil, Seçken \& Yücel, 2004), problemleri çözmede daha başarılı oldukları (Yenice, 2012) ve bu kişilerin davranışlarını daha iyi kontrol ettiğini göstermektedir (Rababah, 2016). Dolayısıyla, bireyin öz-yeterlik inancının farkına varması ve artırması düşük özyeterliği olanlara göre işlerini etkili ve başarılı yapmasını sağlar (Roberts ve ark, 2001).

Bu bilgiler 1şığında öz-yeterlik inançlarının kişiyi önemli biçimde etkileyeceği görüşü ortaya çıkmaktadır. Bireyi yapacağı işi belirlemesi, uygulaması ve başarılı olmasında öz-yeterlik inancının rolü açıkça görülmektedir. O halde, öğretmen adaylarının ilerideki meslek yaşamlarında, öğretim sürecini planlama, uygulama ve değerlendirme aşamalarında kendi öz-yeterlik inançlarından doğrudan etkileneceği varsayılabilir. Öğretmen adaylarının öz-yeterlik inançlarının düşük düzeyde olması olumsuz sonuçlar, yüksek olması halinde ise olumlu sonuçlar doğurabileceği düşünülmektedir. Yüksek düzeyde öz-yeterlik inancı olan öğrenci öğretim sürecini planlamada başarılı etkinlikler, ders planları ve ölçme ve değerlendirme türleri tasarlayabilir.

Öğretimi uygulama aşamasında öğrencilere uygun biçimde dersin konularını sunabilir, gerçek yaşam ile dersin konuları arasında bağlar kurarak konuyu anlatabilir. Öğretimi değerlendirmede ise derse ve konuya göre öğrencilerin performanslarını değerlendirebilir ( Özdemir, 2008). Öz-yeterlik inancı düşük olan ögrenciler ise bu uygulamaları yapamayabilir.

Alanyazına bakıldığında ise yurt içinde ve dışında öğretmen adaylarının öz-yeterlik inançlarıyla ilgili çeşitli çalışmalar yapıldığını görmekteyiz. Bunlardan kısaca bahsetmek gerekirse, David Palmer'in (2006) yaptığı araştırmada çoğu sınıf öğretmeninin başlangıçta fen öğretimindeki öz-yeterlik inançlarının düşük seviyede olduğunu vurgulamış, bu düşük seviyenin artırma yolunun iyi bir biçimde dizayn edilmiş fen dersleriyle olacağını vurgulamıştır.

Çalışkan, Selçuk ve Özcan (2010), "Fizik Öğretmen Adaylarının Öz-Yeterlik İnançları: Cinsiyet, Sınıf Düzeyi Ve Akademik Başarının Etkileri” isimli araştırmalarının sonucunda, öğrencilerin öz-yeterlik inançlarında, akademik başarılarına, sınıf düzeyine ve cinsiyete göre anlamlı farklılıklar olduğu belirlenmiştir.

Tarkın ve Uzuntiryaki (2012), bir çalışmalarında öğretmenlik mesleğini daha çok seven öğrencilerin, öğretim yöntemlerini kullanma ve öğrenciyi derse katmaya yönelik yüksek öz-yeterliğe sahip oldukları bulgusuna ulaşmışlardır.

Kurt ve Ekici (2013), öğretmen adaylarının öğretim süreci öz-yeterlik algısına öğretimde planlama ve değerlendirme dersinin etkisini araştırmışlardır. Araştırmada, dersin pozitif yönde etkisi olduğu belirlenmiştir. 
Lee ve Lee (2014), dersi planlama metodu vasıtasıyla, öğretmen adaylarının teknolojiye entegrasyonlarına yönelik öz-yeterlik inançlarını incelemeye çalışmışlardır. Bu yöntemin, öğrencilerin öz-yeterlik inançları üzerinde etkili olmadığını görmüştür.

Yukarıdaki, araştırmalardan öğretmen adaylarının çeşitli derslere, mesleğe yönelik öğrencilerin öz-yeterlik inançları da ortaya çıkarılmaya çalışılmıştır. $\mathrm{Bu}$ ve benzeri çalışmalar, öğretmen yetiştiren kurumları yeterince aydinlatabilir.

\section{YÖNTEM}

\section{Araştırma Modeli}

Araştırma betimsel yöntem kullanılarak gerçekleştirilmiştir. Bu yöntem olayları açıklamaya çalışır (Kaptan, 1998).

\section{Örneklem/Çalışma Grubu}

$\mathrm{Bu}$ çalışmanın örneklemini, İlköğretim Matematik Eğitimi dördüncü sınıfta öğrenim gören 98 öğrenci oluşturmaktadır. 98 öğrencinin 78' i kız, 20' si ise erkektir.

Aşağıdaki tabloda örneklemi oluşturan öğrencilerin demografik bilgileri verilmiştir.

\section{Tablo 1.}

İlkögretim Matematik Öğretmeni Adaylarının Demografik Bilgileri

\begin{tabular}{llll}
\hline Kişisel Bilgiler & & $\mathrm{f}$ & $\%$ \\
\hline \multirow{3}{*}{ Cinsiyet } & 1.Kız & 78 & 79.6 \\
& 2.Erkek & 20 & 20.4 \\
& Toplam & 98 & 100.0 \\
\hline & 1.Düz Lise & 21 & 21.4 \\
& 2.Anadolu Lisesi & 44 & 44.9 \\
& 3.Anadolu Öğretmen Lisesi & 25 & 25.5 \\
Mezun Olunan Lise & 4.Özel Lise & 3 & 3.1 \\
& 5.Meslek Lisesi & 3 & 3.1 \\
& 6.Diğer & 2 & 2 \\
& Toplam & 98 & 100.0 \\
\hline \multirow{3}{*}{ Tercih Sirasi } & 1. 1-5. Sira & 77 & 78.6 \\
& 2. 6-10. Sira & 11 & 11.2 \\
& 3. 11 ve Üstü Sıra & 10 & 10.2 \\
& Toplam & 98 & 100.0 \\
\hline \multirow{5}{*}{ Tercih Nedeni } & 1. Kendim İstedim & 67 & 68.4 \\
& 2. Ailem İstedi & 5 & 5.1 \\
& 3. İs Garantisi Olduğu İçin & 11 & 11.2 \\
& 4. Boşta Kalmamak İçin & 11 & 11.2 \\
& 5. Çevrem İstediği İçin & 4 & 4.1 \\
& Toplam & 98 & 100.0 \\
\hline Öğretmenlikten Başka İş Yapmaya & 1. Kararsızım & 10 & 10.2 \\
Yönelik Tutum & 2. Hayır & 88 & 89.8 \\
& Toplam & 98 & 100.0 \\
\hline
\end{tabular}

Araştırmaya katılan öğrencilerin \% 79.6' s1 k1z, \% 20.6' s1 erkek öğrencilerden oluşmaktadır. Öğretmen adaylarının \%21.4' ü düz liseden, \% 44.9'u Anadolu lisesinden, \% 25.5'i Anadolu öğretmen lisesinden, \% 3.1'i özel lise ve meslek liselerinden, \% 2'si ise, diğer liselerden mezun olmuşlardır. Öğrencilerin \%78.6's1 okudukları bölümleri 1-5 sırada, \%11,2'si 6-10 Sırada, \% 10,2'si 11 ve üstü sırada; öğretmen adaylarının \% 68.4 kendileri, \% 5.1'i aileleri , \% 4.1'i çevreleri istedikleri, \%11.2'si iş garantisi olduğu ve boşta kalmamak 
için bölümü tercih etmiştir. Araştırmaya katılan öğrencilerin \%89.8'i öğretmenlikten başka iş yapmayacaklarını, \% 10.2'si ise kararsız olduklarını belirtmişlerdir.

Araştırmanın çoğunluğunu kız öğrenciler oluşturmaktadır. Öğretmen adaylarının çoğu Anadolu lisesinden, çok azı ise diğer liselerden mezun olmuşlardır. İlköğretim matematik eğitimini 1-5 sırada tercih edenlerin sayıs1, 6-10 ve 11 ve üstü sırada tercih edenlerden daha fazladır. Öğrencilerin bölümü neden tercih ettikleri sorusuna alınan cevaplar arasında kendim istedim cevabı başı çekmektedir. Sonuçlar incelendiğinde, ben bu mesleği yapacağım diyenler büyük çoğunlukta, karasızım azınlıkta ve ben bu mesleği yapmayacağım, diyenler ise olmamıştır.

\section{Veri Toplama Araçları ve Süreçleri}

\section{Öğretim Sürecine İlişkin Öz-Yeterlik İnancı Ölçeği}

Veriler, Özdemir (2008) in "Öğretim Sürecine İlişkin Öz-Yeterlik İnancı Ölçeği ” ile toplanmıştır. Yapılan güvenirlik analizinde iç tutarlılık katsayısı 0,882 olarak bulunmuştur. Ölçekte 40 madde vardır. Bu maddelerden, planlama boyutunda "Ders planında amaçlara uygun strateji, yöntem ve teknikler belirleyebilirim", “ Kimsenin yardımı olmadan bir yıllık plan hazırlayabilirim”, "Ders planında bilgi ve iletişim teknolojilerinin nasıl kullanılacağına yer verebilirim"; uygulama boyutunda "Dersin konularıyla gerçek yaşam arasında ilişki kurarak konuyu anlatabilirim", "Gerektiğinde alternatif materyal, strateji ve etkinlikler geliştirebilirim", değerlendirme boyutunda ise "Derse ve konuya uygun değerlendirme ölçütleri belirleyebilirim", "Öğrencilerin duyuşsal özelliklerini (kendine güven, öz-yeterlik vs.) her dersin özelliğine uygun şekilde değerlendirebilirim”, "Geliştirdiğim ölçme aracının (başarı testi ve tutum ölçeği) geçerlik ve güvenirliğini test edebilirim" cümlelerini örnek verebiliriz. Ölçek beşli Likert tipi biçimindedir. 1 "hiç katılmıyorum", 2 "katılmıyorum", 3 "kararsızım", 4 "katılıyorum" ve 5 "tamamen katılıyorum" şeklindedir (Özdemir, 2008).

\section{Verilerin Analizi}

Verilerin analizinde SPSS programından yararlanılmıştır. Grup puanlarında varyansların homojenliği için Levene testi uygulanmıştır. Bu testin sonuçlarına göre sadece ölçeğin panlama boyutunda, öğrencilerin öğrenim görülen branşı tercih nedenine göre varyansların homojen olmadığı, fakat diğer grup puanlarında varyansların homojen olduğu sonucu bulunmuştur. Belirtilen sonuçlara göre öz-yeterlik inançlarının cinsiyete göre farklılaşma durumunu belirlemek amacıyla bağımsız gruplar $t$ testi kullanılmıştır. Mezun olunan liseye, öğrenim görülen branşı tercih sırasına, öğretmenlikten başka bir iş yapmaya yönelik tutuma göre, ölçeğin planlama, uygulama ve değerlendirme alt boyutlarında farklılaşma durumunu ortaya koymak için tek yönlü varyans analizinden faydalanılmıştır. Öğrenim görülen branşı tercih nedenine göre farklılaşma durumunu ortaya koymak için, ölçeğin uygulama ve değerlendirme boyutunda yine tek yönlü varyans analizinden faydalanılmıştır. Ölçeğin planlama boyutunda öğrenim görülen branşı tercih nedenine göre farklılaşma durumunun sonucunu görmek için ise, Kruskal-Wallis testi kullanılmıştır. 


\section{BULGULAR}

Aşağıda ilgili çalışma hakkında elde edilen bulgu ve yorumlar verilmiştir.

Tablo 2.

Öz-Yeterlik Inançlarının Cinsiyete Göre Farklılaşma Durumu

\begin{tabular}{|c|c|c|c|c|c|c|c|}
\hline Boyutlar & Cinsiyet & $\mathrm{n}$ & $\bar{X}$ & $\mathrm{SS}$ & $\mathrm{Sd}$ & $\mathrm{t}$ & $\mathrm{P}$ \\
\hline \multirow[t]{2}{*}{ Planlama } & $\mathrm{K}_{1 \mathrm{z}}$ & 78 & 3.75 & 0.47 & 96 & 0.013 & 0.534 \\
\hline & Erkek & 20 & 4.05 & 0.42 & & & \\
\hline \multirow[t]{2}{*}{ Uygulama } & $\mathrm{K}_{1 z}$ & 78 & 3.87 & 0.42 & 96 & 0.210 & 0.831 \\
\hline & Erkek & 20 & 4.00 & 0.47 & & & \\
\hline \multirow[t]{2}{*}{ Değerlendirme } & $\mathrm{K}_{1 \mathrm{Z}}$ & 78 & 3.94 & 0.40 & 96 & 0.288 & 0.281 \\
\hline & Erkek & 20 & 4.05 & 0.46 & & & \\
\hline
\end{tabular}

Tabloya göre, erkek öğrencilerin öz-yeterlik inançları puanları kız öğrencilerden daha yüksek olmasına rağmen, kız ve erkek öğrencilerin öz-yeterlik inançları arasında ölçeğin alt boyutları için anlamlı bir farklılık görülmemektedir. $(\mathrm{p}>0.05$ tplanlama $=0.013$; tuygulama $=0.210$; tdeğerlendirme $=0.288$,$) . Buna göre,$ öğrencilerin öz-yeterlik inançları için, cinsiyet değişkeninin önemli bir faktör olmadığg söylenilebilir.

\section{Tablo 3.}

Öz-Yeterlik İnançlarının Mezun Olunan Liseye Göre Farklılaşma Durumu

\begin{tabular}{|c|c|c|c|c|c|c|}
\hline Boyutlar & Mezun Olunan Lise & $\mathrm{N}$ & $\bar{X}$ & $S$ & $\mathrm{~F}$ & $\mathrm{P}$ \\
\hline \multirow{7}{*}{ Planlama } & Düz lise & 21 & 3.82 & 0.56 & 0.347 & 0.883 \\
\hline & Anadolu Lisesi & 44 & 3.82 & 0.49 & & \\
\hline & Anadolu Öğretmen Lisesi & 25 & 3.75 & 0.42 & & \\
\hline & Özel lise & 3 & 4.08 & 0.57 & & \\
\hline & Meslek lisesi & 3 & 3.91 & 0.19 & & \\
\hline & Diğer & 2 & 3.62 & 0.35 & & \\
\hline & Toplam & 98 & 3.81 & 0.48 & & \\
\hline \multirow{8}{*}{ Uygulama } & Düz lise & 21 & 3.89 & 0.51 & 0.298 & 0.913 \\
\hline & Anadolu Lisesi & 44 & 3.89 & 0.44 & & \\
\hline & Anadolu Öğretmen Lisesi & 25 & 3.87 & 0.38 & & \\
\hline & Özel lise & 3 & 4.19 & 0.33 & & \\
\hline & Meslek lisesi & 3 & 3.94 & 0.39 & & \\
\hline & Diğer & 2 & 3.84 & 0.29 & & \\
\hline & Toplam & 98 & 3.89 & 0.43 & & \\
\hline & Düz lise & 21 & 3.90 & 0.47 & 0.176 & 0.971 \\
\hline \multirow{5}{*}{ Değerlendirme } & Anadolu Lisesi & 44 & 3.98 & 0.40 & & \\
\hline & Anadolu Öğretmen Lisesi & 25 & 3.96 & 0.40 & & \\
\hline & Özel lise & 3 & 3.94 & 0.65 & & \\
\hline & Meslek lisesi & 3 & 4.05 & 0.38 & & \\
\hline & Diğger & 2 & 4.11 & 0.38 & & \\
\hline
\end{tabular}




\section{$\begin{array}{llll}\text { Toplam } & 98 & 3.96 & 0.41\end{array}$}

Tabloya göre, öğretmen adaylarının mezun oldukları liselere göre öğretimi planlama, uygulama ve değerlendirme alt boyutlarında öz-yeterlik inançları puan ortalamalarıyla ilgili varyans analizi sonuçları anlamsız bulunmuştur. Bu durumda, öğrencilerin mezun oldukları liselere göre öz-yeterlik inançları farklılaşmamaktadır.

Tablo 4.

Öz-Yeterlik İnançlarının Öğrenim Görülen Branşı Tercih Sırasına Göre Farklılaşma Durumu

\begin{tabular}{|c|c|c|c|c|c|c|}
\hline Boyutlar & Tercih Siras1 & $\mathrm{N}$ & $\bar{X}$ & $\mathrm{~S}$ & $\mathrm{~F}$ & $\mathrm{P}$ \\
\hline \multirow{4}{*}{ Planlama } & 1-5. Sira & 77 & 3.81 & 0.46 & 0.001 & 0.999 \\
\hline & 6-10. Sira & 11 & 3.81 & 0.68 & & \\
\hline & 11 ve Üstü Sıra & 10 & 3.81 & 0.42 & & \\
\hline & Toplam & 98 & 3.81 & 0.48 & & \\
\hline \multirow{4}{*}{ Uygulama } & 1-5. Sira & 77 & 3.88 & 0.45 & 0.382 & 0.683 \\
\hline & 6-10. Sira & 11 & 4.00 & 0.39 & & \\
\hline & 11 ve Üstü Sıra & 10 & 3.91 & 0.32 & & \\
\hline & Toplam & 98 & 3.89 & 0.43 & & \\
\hline \multirow{4}{*}{ Değerlendirme } & 1-5. Sira & 77 & 3.95 & 0.41 & 1.383 & 0.256 \\
\hline & 6-10. Sira & 11 & 4.16 & 0.41 & & \\
\hline & 11 ve Üstü Sıra & 10 & 3.90 & 0.39 & & \\
\hline & Toplam & 98 & 3.96 & 0.41 & & \\
\hline
\end{tabular}

Bu sonuçlara göre, öğrencilerin öğrenim görülen branşı tercih sırasına göre, öğretimi planlama, uygulama ve değerlendirme alt boyutlarında öz-yeterlik inançları puan ortalamalarıyla ilgili varyans analizi sonuçları anlamsız olarak bulunmuştur ( $\mathrm{p}>0.05 \mathrm{~F}=0.001, ; \mathrm{F}=0.382, ; \mathrm{F}=1.383$,). Elde edilen sonuca göre, öğrencilerin öğrenim gördükleri branş1 1-5., 6-10. ve 11 ve üstü sıradaki tercih sıralamalarıyla, öz-yeterlik inançları farklılaşmamaktadır.

\section{Tablo 5.}

Öz-Yeterlik Inançlarının Planlama Boyutunda Öğrenim Görülen Branşı Tercih Nedenine Göre Farklılaşma Durumu

\begin{tabular}{llccccc}
\hline Boyutlar & Tercih Nedeni & $\mathrm{N}$ & Sıra Ort. & $\mathrm{Sd}$ & $\mathrm{X}^{2}$ & $\mathrm{P}$ \\
\hline \multirow{3}{*}{ Planlama } & Kendim İstedim & 67 & 50.67 & 4 & 0.865 & 0.929 \\
& Ailem İstedi & 5 & 54.50 & & & \\
& İş Garantisi Olduğu İçin & 11 & 44.91 & & & \\
& Boşta Kalmamak İçin & 11 & 47.14 & & & \\
& Çevrem İstediği İçin & 4 & 42.75 & & & \\
\hline
\end{tabular}

Bu sonuçlara göre, öğretmen adaylarının öğrenim görülen branşı tercih nedenine göre, öğretimi planlama alt boyutlarında öz-yeterlik inançları puan ortalamalarıyla ilgili varyans analizi sonuçları $\mathrm{p}>0.05$ önem 
düzeyinde istatistiksel olarak anlamsız bulunmuştur. Araştırmaya katılan öğrencilerin öz-yeterlik inançları, planlama boyutunda öğrenim görülen branşı tercih nedenine göre farklılaşmadığ sonucu ile karşılaşılmaktadır.

\section{Tablo 6.}

Öz-Yeterlik İnançlarının Uygulama Ve Değerlendirme Boyutunda Öğrenim Görülen Branşı Tercih Nedenine Göre Farklılaşma Durumu

\begin{tabular}{llccccc}
\hline Boyutlar & Tercih Nedeni & $\mathrm{N}$ & $\bar{X}$ & $\mathrm{~S}$ & $\mathrm{~F}$ & $\mathrm{P}$ \\
\hline \multirow{3}{*}{ Uygulama } & Kendim İstedim & 67 & 3.91 & 0.40 & 1.363 & 0.253 \\
& Ailem İstedi & 5 & 4.05 & 0.45 & & \\
& İş Garantisi Olduğu İçin & 11 & 3.69 & 0.57 & & \\
& Boşta Kalmamak İçin & 11 & 4.01 & 0.39 & & 0.140 \\
& Çevrem İstediği İçin & 4 & 3.64 & 0.47 & & \\
& Toplam & 98 & 3.89 & 0.43 & & \multirow{2}{*}{0.775} \\
Keğerlendirme & Kendim İstedim & 67 & 3.98 & 0.39 & & \\
& Ailem İstedi & 5 & 4.24 & 0.37 & & \\
& İş Garantisi Olduğu İçin & 11 & 3.81 & 0.42 & & \\
& Boşta Kalmamak İçin & 11 & 4.04 & 0.51 & & \\
& Çevrem İstediği İçin & 4 & 3.61 & 0.32 & & \\
& Toplam & 98 & 3.96 & 0.41 & & \\
\hline
\end{tabular}

Tablo 6 incelendiğinde öğretmen adaylarının, öğretimi uygulama ve değerlendirme alt boyutlarında özyeterlik inançlarının öğrenim görülen branşı tercih nedenlerine göre istatistiksel açıdan anlamlı olarak farklılaşmamıştır. Tablo 6'dan çıkan sonucun ardından şunu söyleyebiliriz; öğrenim görülen branşı tercih nedeni, öğretim sürecine yönelik öz-yeterlik inançları üzerinde anlamlı bir farklılık ortaya koymamıştır.

\section{Tablo 7.}

Öz-Yeterlik Inançlarının Öğretmenlikten Başka Bir İş Yapmaya Yönelik Tutuma Göre Farklılaşma Durumu

\begin{tabular}{lllllll}
\hline \multirow{2}{*}{ Boyutlar } & Öğretmenlikten Başka İş Yapmaya & $\mathrm{N}$ & $\bar{X}$ & $\mathrm{~S}$ & $\mathrm{~F}$ & $\mathrm{P}$ \\
& Yönelik Tutum & & & & & \\
\hline \multirow{3}{*}{ Planlama } & Kararsızım & 10 & 3.76 & 0.48 & 0.125 & 0.724 \\
& Hayır & 88 & 3.81 & 0.46 & & \\
& Toplam & 98 & 3.81 & 0.48 & & \\
\hline \multirow{3}{*}{ Uygulama } & Kararsızım & 10 & 3.79 & 0.44 & 0.642 & 0.425 \\
& Hayır & 88 & 3.91 & 0.30 & & \\
& Toplam & 98 & 3.89 & 0.43 & & \\
\hline \multirow{3}{*}{ Değerlendirme } & Kararsızım & 10 & 3.83 & 0.42 & \multirow{2}{*}{1.212} & 0.274 \\
& Hayır & 88 & 3.98 & 0.37 & & \\
\hline
\end{tabular}

Öğretmenlikten başka bir iş yapmaya yönelik öğrencilerin öz-yeterlik inançları arasında ölçeğin alt boyutları 
için anlamlı bir farklılık elde edilememiştir ( $p>0.05 \mathrm{~F}=0.125 ; \mathrm{F}=0.642 ; \mathrm{F}=1.212) \mathrm{Bu}$ bağlamda, öğretmenlikten başka iş yapmaya yönelik tutum ile öğrencilerin öz-yeterlik inançları arasında anlamlı bir farklılık yoktur denilebilir. Ayrıca, "Öğretmenlikten başka iş yapacak mısınız?" sorusuna" hayır” biçiminde cevaplayan öğretmen adayı öğrencilerin öz-yeterlik inanç puanları "kararsızım” diyenlerden daha yüksek düzeydedir.

\section{TARTIŞMA ve SONUÇ}

$\mathrm{Bu}$ bölümde, araştırma sonuçları ve önerileri sunulmuştur.

Öğrencilerin çoğunluğunun, ilköğretim matematik eğitimini 1-5. sirada tercih etmeleri, kendi istekleriyle tercih etmeleri, mezun olduktan sonra bu mesleği yapmak istemeleri oldukça mutluluk vericidir. Bu sonuç, araştırmaya katılan öğrencilerimizin öğretmenlik mesleğini benimsediklerinin göstergesi olabilir. Bundan dolayı öğrenim sürecinden başlayan ve mesleği yürütmenin her aşamasında oluşacak başarı adımları oluşmaması imkansızdır (Tanrı̈̈̆gen, 1997).

Araştırmada kız ve erkek öğrencilerin öz-yeterlik sonuçları farklılaşmamıştır. Bu çalışmanın bulgularına benzer olarak, Lin ' in (2016), yaptığ çalışmada öz-yeterlik inançları açısından kız ve erkek öğrenciler arasında bir farklılaşmaya rastlanılmamıştır. Ayrıca Uysal ve Kösemen'in (2013) öğretmen adaylarının genel öz-yeterlik inançları incelenmesi çalışmalarında kız ve erkek öğrencilerin öz-yeterlikleri inançlarının farklılaşmadığı sonucunu bulmuşlardır. Kız ve erkek öğrencilerin, aynı programı görmeleri farklılık olmamasının bir sebebi olarak gösterilebilir. Bu araştırmada erkek öğrencilerin, kız öğrencilere nazaran öğretimi planlama, uygulama ve değerlendirmeye ilişkin öz-yeterlik inanç puanları daha yüksek bulunmuştur. Uysal ve Kösemen'in (2013), öğretmen adaylarının genel öz-yeterlik inançları incelenmesi çalışmalarında da, erkek öğrencilerin öz-yeterlik inançları, kız öğrencilere göre yüksek olduğu sonucunu bulmuşlardır. Araştırmada elde edilen sonuçla ilgili olarak, erkek öğrencilerin öğretmenlik mesleğine bakış açılarının olumlu yönde olduğunu söyleyebiliriz. Kız öğrencilerin de öğretmenlik mesleğine bakış açılarının bu yönde olması için, öğretim sürecinin her aşamasında öz-yeterlik inançlarının olumlu şekilde gelişmesi, öğretim sürecinde sağlanmalıdır. Çünkü olumlu öz-yeterliğe sahip bireyler, beceri ve kapasitelerini yansıtırlar, verilen bir görevi başarılı bir şekilde tamamlamaları için kendilerine güven duyarlar (Kele \& Sharma, 2014). Bu durumda yapılacak etkinlikler aşağıdaki şekilde verilmeye çalışılmıştır. Bireyin doğrudan kendi deneyimlediği yaşantıları sağlayacak düzenlemeler basamağında, öğrenciye öğretim süreciyle ilgili doğrudan deneyimlerle tanıştırılmalıdır. Örneğin bir ders konusu üzerinde, konunun planlamasından değerlendirilmesine kadar çeşitli görevler verilmelidir. Bu görev çerçevesinde yanlışlar düzeltilerek, eksikler tamamlanmalıdır. Bu iş birkaç kez yapılarak öğrencinin başarı doyumuna ulaşması sağlanmalıdır. Dolaylı yaşantılar aşamasında, öğretim süreciyle ilgili başarılı deneyimler sergilenerek, bireyin kendi performansıyla yüzleşmesi sağlanmalıdır. Örneğin, başarılı öğrenci davranışları sınıfta örnek olarak gösterilebilir (Arslan, 2012). Öğrenci bir şeyleri gerçekleştirirken, yaptığın şey doğru, sen çok daha iyi yapıyorsun, sen bu işi yaparsın, en iyi şekilde başarırsın bu ve benzeri cümleler kullanılması özyeterliğin gelişmesine katkıda bulunur (Schunk, 1985). Bu nedenle, sözel ikna yolu ile öğrencilerimizin öz yeterlik inancını artırabiliriz. Dördüncü ve son kısım olan psikolojik durumda ise, öğretmen adaylarına öğretim süreciyle ilgili bütün basamaklar öğretilirken, akademisyenlerimiz, iletişimde başarılı, demokrat bir lider olmalılar ve olumlu bir sınıf atmosferi oluşturmalılar. Yukarıda verilen öneriler sayesinde öğrencide başarılı yaşantılar, dolayısıyla olumlu yönde gelişen öz-yeterlik elde edilebilir (Arslan, 2012).

Bütün öğrenciler, iyi bir öğretmende bulunması gereken mesleki nitelikler çatısı altında verilen konu alanı bilgisi, genel kültür, mesleki beceri ve yeterlilikleri kapsayan tüm dersleri almaktadırlar. Mezun olunan liseye, tercih sıralamalarına ve öğrenim görülen branşı tercih nedenlerine göre öğrencilerin öz-yeterlik inançları puanlarının farklılaşmaması, öğretmen olma yolunda bütün öğrencilerin dört sene boyunca aynı eğitim ve öğretimden geçmelerine bağlanabilir. 
“Öğretmenlikten başka iş yapacak mısınız?" sorusuna" hayır” biçiminde cevaplayan öğretmen adayı öğrencilerin öz-yeterlik inanç puanları "kararsızım" diyenlerden daha yüksek düzeydedir. Bu durum memnun edici sonuçlardan birisidir. Öğretmenler, öğrencilerin öğrenmelerine katkıda bulunan en önemli faktördürler (Kanadlı, 2016). Etkili bir öğretmenin nasıl olacağına ilişkin birçok özellik vardır. Bunlardan birisi ise, öz-yeterlik inancıdır (Ekinci,2012). Öğretmen öz-yeterliği pozitif öğretme ve öğrencinin öğrenmesine sürekli etki eden faktörlerden biridir (Groshit \& Hen,2014). Öğretmen öz-yeterliği motivasyonu etkiler (Sarfo, Amankwah, Sam \& Konin, 2015) ve sınıftaki öğretmen etkililiğini şekillendiren önemli bir etkendir. Öz-yeterliği yüksek olan öğretmenler öğretimleri esnasında daha esnektirler ve öğrencilerine yardım etmek için çaba harcarlar. Yüksek öz-yeterliğe sahip öğretmenler, anlaşılması zor olan şeyleri öğrencilerine etkili bir şekilde öğreteceklerine inanırlar (Malinauskas, 2017). Aksine öz-yeterliği düşük olan öğretmenler ise bütün öğrencilerinin öğrenme ihtiyaçlarına tam anlamıyla cevap veremezler (Pendergast, Garvis \& Keogh, 2011).

Yukarıdaki ifadelerden sonra, bu mesleği yapmak isteyen öğrencilerin öğretimi planlaması, uygulaması ve değerlendirmesi alt boyutlarında öz-yeterlik inançlarının güçlü olmasına yönelik ihtiyacın varlığı açıkça görülmektedir.

\section{KAYNAKÇA}

Arslan, A. (2012). İlköğretim Öğrencilerinin Öz-Yeterlik İnanc1 Kaynaklarının Öğrenme ve Performansla İlgili Öz-Yeterlik İnancını yordama Gücü. Kuram ve Uygulamada Eğitim Bilimleri, 12(3), 1907-1920.

Capri, B., Ozkendir,O., Ozkurt, B. \& Karakus,F. (2012). General Self-Efficacy Beliefs, Life Satisfaction, Burnout of University Students. Procedia Social and Behavioral Sciences, 47, 968-973.

Çalışkan, S., Selçuk, G., S. \& Özcan, Ö. (2010). Fizik öğretmen adaylarının Özyeterlik inançları: Cinsiyet, Sınıf Düzeyi, ve Akademik Başarının Etkileri. Kastamonu Eğitim Dergisi, 18(2), 449-466.

Çolak, İ., Yorulmaz Y., İ., \& Y., Altınkurt (2017). Öğretmen Özyeterlik İnancı Ölçeği Geçerlik ve Güvenirlik Çalışması. MSKU Eğitim Fakültesi Dergisi, 4(1), 20-32.

Duman, B. (2010). Öğrenme Öğretme Sürecindeki Hata Yanılsama ve Yanıltmacalara İlişkin Öğrenci Görüsleri. Muğla Üniversitesi Sosyal Bilimler Enstitüsü Dergisi, 25, 15-40.

Ekinci, N. (2012). Teacher Self-Efficacy Beliefs of Candidate Teachers in Education Faculty and Pedagogical Formation Program. Educational Process: International Journal, 1(2), 19-28.

Goroshit, M. \& Hen, M. (2014). Does Emotional Self-Efficacy Predict Teachers' Self Efficacy and Empathy? Journal of Education and Training Studies, 2(3), 26-32.

Kanadl1, S. (2016). Prospective Teachers' Professional Self-Efficacy Beliefs in Terms of Their Perceived Autonomy Support and Attitudes towards the Teaching Profession A Mixed Methods Study. Educational Sciences: Theory and Practice, 17(5), 1847-1871.

Kaptan,, S., (1998). Bilimsel Araştırma ve İstatistik Teknikleri, Tekışık Web Ofset Tesisleri, Ankara, 59-73.

Kele, A. \& Sharma, S. (2014). Students' beliefs about learning Mathematics: Some Findings from the Solomon Islands. Teachers and Curriculum, 14, 33-44.

Koç, C. (2013). Sınıf Öğretmenlerinin Öz Yeterlik Algıları ve Yapılandırmacı Öğrenme Ortamı Oluşturma Becerilerinin İncelenmesi. Hacettepe Üniversitesi Ĕ̈itim Fakültesi Dergisi, 1, 240-255.

Kurt, H. \& Ekici, G. (2013). Öğretimde Planlama ve Değerlendirme Dersinin Öğretmen Adaylarının Öğretim Süreci Öz-Yeterlik Algısına Etkisi. Elementary Education Online, 12(4), 1157-1172.

Klassen, R., M., \& Klassen, J., R., L. (2018). Self-Efficacy Beliefs of Medical Students: A Critical Review. Perspectives on Medical Education, 7, 76-82. 
Lee, Y. \& J. Lee (2014). Enhancing Preservice Teachers' Self-efficacy Beliefs for Techonology Integration throgh Lesson Planning Practice. Computers \& Education, 73, 121-128.

Lin1, G. (2016). Self-Efficacy Beliefs and Their Sources in Undergraduate Computing Disciplines: An Examination of Gender and Persistence. Journal of Educational Computing Research, 53(4), 540-561.

Malinauskas, R., K. (2017). Enhancing of Self Efficacy in Teacher Education Students. European Journal of Contemporary Education, 6(4), 732-738.

Mart, V., D., Filip, D., Mien, S. (2011). Factors Affecting Student's Self Efficacy in Higher Education. Educational Research Review 6(2), 95-108.

Morgil, İ., Seçken, N. \& Yücel,A., S. (2004). Kimya Öğretmen Adaylarının Öz-yeterlik İnançlarının Bazı Değişkenler Açısından İncelenmesi. BÄ̈ Fen Bilimleri Enstitüsü Dergisi, 6.(1),62-72.

Özdemir, S., M. (2008). Sınıf Öğretmeni Adaylarının Öğretim Sürecine İlişkin Öz-Yeterlik İnançlarının Çeşitli Değişkenler Açısından İncelenmesi. Kuram ve Uygulamada Eğitim Yönetimi, 54, 277-306.

Palmer, D. (2006). Durability of Changes in Self-efficacy of Preservice Primary Teachers. International Journal of Science Education, 28(6), 655-671.

Pendergast, D., Garvis, S. \& Keogh, J. (2011). Pre-Service Student-Teacher Self-Efficacy Beliefs: An Insight Into the Making Teachers. Australian Journal of Teacher Education, 36(12), 45-57.

Rababah, M., M., S. (2016). Social Self-Efficacy and its Relationship with both Depression and Anxiety, Stress among a Sample of Jadara University Students. Journal of Education and Practice, 7(35), 8489.

Roberts, J.,K., Henson, R., K., Tharp, B., Z. \& Moreno, N., P. (2001). An Examination of Change in Teacher Self-efficacy Beliefs in Science Education Based on the Duration of Inservice Activities. Journal of Science Teacher Education, 12(3), 199-213.

Salem A. ,A., M., S. \& Mosaad Abu, A., D. (2014). Writing Anxiety as a Predictor of Writing Self Efficacy in English for Special Education Arab Learners. International Education Studies, 7(6), 128-134.

Sarfo, F., K., Amankwah, F., Sam, F., K. \& Konin, D. (2015). Teacher's Self-Efficacy Beliefs: The Relationship Between Gender and Instructional Strategies, Classroom and Management and Student Engagement. Ghana Journal of Development Studies, 12(1), 19-32.

Schunk, D., H. (1985). Self- Efficacy and Classroom Learning. Psychology in The Schools, 22(2), 208-223.

Tanrı̈ğen. A. (1997). Buca Eğitim Fakültesi Öğrencilerinin Öğretmenlik Mesleğine Yönelik Tutumları. PAÜ Eğitim Fakültesi Dergisi, 3, 55-67.

Tarkın, A. \& Uzuntiryaki, E. (2012). Investigation of Pre-Service Teachers' Self-Efficacy Beliefs and Attitudes toward Teaching Profession through Canonical Analysis. Elementary Education Online, 11(2), 332-341.

Uysal, İ. \& Kösemen, S. (2013). Öğretmen Adaylarının Genel Öz-Yeterlik İnançlarının İncelenmesi. Eğgitim ve Öğretim Araştırmaları Dergisi, 2(2), 217-226.

Yenice, N., (2012). Öğretmen Adaylarının Öz-yeterlik Düzeyleri ile Problem Çözme Becerilerinin İncelenmesi. Elektronik Sosyal Bilimler Dergisi, 11(39), 36-58.

Webb-Williams, J. (2014). Gender Differences in School Children's Self-Efficacy Belief: Students' and Teachers' Perspectives. Academic Journals, Educational Research and Reviews, 9(3), 75-82. 


\section{EXTENDED ABSTRACT}

Various factors play a role in the development of education and teaching. One of these is the teacher factor. It is assumed that the teacher who carries out his profession with success and affection is one of the most important sources for education and teaching. For this reason, it is considered that the determination of preservice elementary mathematics teachers' self-efficacy beliefs towards teaching Process may contribute to how succesful they will be in their future profession.

In this study, it was aimed to determine preservice elementary mathematics teachers' self-efficacy beliefs towards teaching Process according to gender, graduated high school, orders and reasons of preference the program that enrolled and their attitudes towards teaching professionThe main problem of this research is to examine preservice elementary mathematics teachers' self-efficacy beliefs towards teaching Process

The first sub problem is whether the self-efficacy beliefs of preservice teacher vary according to the gender variable, The second sub-problem is whether the self-efficacy beliefs of preservice teacher vary according to the graduated high school variable, The third sub-problem is whether the self-efficacy beliefs of preservice teacher vary according to the order of preference. The fourth sub-problem is whether the self-efficacy beliefs of preservice teacher change according to the reasons preference variable, The fifth sub-problem is whether the self-efficacy beliefs of the preservice teacher vary according to the teaching profession.

The current study was performed by using the survey scan model. The variables are gender, graduated high school, order of preference, reasons preference and teaching profession. The participants of the study are 98 senior students of primary education mathematics teaching department,Kazım Karabekir Faculty of Education at Ataturk University. 78 of the students are female and 20 are male.

The " Self-Efficacy Beliefs Towards Teaching Process Scale" developed by Soner Mehmet Özdemir was used in this study.Factor analysis has been applied forconstruct validity of the scale, and for reliability, Cronbach Alfa has been applied as internal consistency co-efficient. The scale has displayed a three factor structure in the factor analysis carried out. It is observed that these three sub-factors have explained $41.95 \%$ of the variance within the whole scale points. The first factor explains $20.21 \%$, the second one explains $11.04 \%$, and the third factor explains $10.34 \%$ of the total variance. These three factors were named planning, application and assessment. The results of the co-efficient of reliability were $.668, .839, .756$ and .882 for planning subscale, applicationsubscale, assessment subscale and total score, respectively. The scale consists of 40 items in total and there were 8 items in the first subscale, 19 items in the second and 13 items in the last scale.This scale is a 5-choice Likert-type scale ranging from strongly agree to strongly disagree.

Firstly, personal information of prospective mathematics teacher participating in the research was obtained. Percentage, frequency values were obtained for this information. the Levene Test was used for the homogeneity of the variances. Tests were used according to normality and homogeneity assumptions to illuminate the main problem of the research.

According to the result of the research, it is obtained that preservice elementary mathematics teachers' self-efficacy beliefs towards teaching process according to gender, graduated high school, orders and reasons of preference the program that enrolled and their attitudes towards teaching profession don't differ.It is very pleasing that the majority of students prefer primary and fifth grade mathematics education and want to do this profession after graduation. Female and male students' self-efficacy results don't differ in the study.

In this study, self-efficacy beliefs of male students about planning, application and evaluation of teaching were found to be higher than female students. Regarding the results of the study, we can say that male students' point of view towards teaching profession is positive. Preservice elementary mathematics teachers' self-efficacy beliefs towards teaching process according to graduated high school, orders and reasons of preference the program that enrolled towards teaching profession don't differ.

The self-efficacy beliefs of the teacher candidates who say no to the question "Are you going to do other profession than teaching profession?" are higher than those who say "Undecided".It is very pleasing that the majority of students prefer primary and fifth grade mathematics education and want to do this profession after graduation. This result may 
indicate that our students have adopted the teaching profession. Female and male students' self-efficacy results don't differ in the study. The reason why there is no difference may be that female and male see the same program.

In order to the female students to view the teaching profession in this direction, a positive development of self-efficacy beliefs should be provided in the teaching process at every stage of the teaching process. Preservice elementary mathematics teachers' self-efficacy beliefs towards teaching process according to graduated high school, orders and reasons of preference the program that enrolled towards teaching profession don't differ. We may say that the sama education and training of the students can cause these results. The self-efficacy beliefs of the teacher candidates who say no to the question "Are you going to do other profession than teaching profession?" are higher than those who say "Undecided". This is a very satisfying result for us. 